\title{
Reading is Vital, but will it be Invisible? Screens vs. Paper on Our Way to the Naturalized Technology of Reading
}

\author{
Jarosław Kowalski \\ Laboratory of Interactive \\ Technologies, National \\ Information Processing Institute, \\ al. Niepodległości 188b, 00-608, \\ Warsaw, Poland \\ Email: jkowalski@opi.org.pl
}

\author{
Piotr Toczyski \\ Faculty of Applied Social Sciences, \\ Maria Grzegorzewska University \\ Szczęśliwicka 40, \\ 02-353 Warsaw, Poland \\ Email: ptoczyski@aps.edu.pl
}

\author{
Cezary Biele, \\ Aldona Zdrodowska \\ Laboratory of Interactive \\ Technologies, National \\ Information Processing Institute, \\ al. Niepodległości 188b, 00-608, \\ Warsaw, Poland \\ Email: \{cbiele, \\ azdrodowska\}@opi.org.pl\}
}

\begin{abstract}
This analytical position paper aims to open a discussion on the future of the naturalized technology of reading. Our analysis contributes to the discussion that we think scholars in human-computer interaction should adopt from other disciplines. We begin with a seven-level technology pyramid which ends with naturalized technology. We look for the place of paper and digital books in this pyramid, currently somewhere between invisible and vital technologies. We discuss scenarios for the book, using current theories of reading from both philosophical and neuropsychological viewpoints. Finally, we show inspiring quantitative and qualitative data gathered during "total research" into the literary culture. They illustrate the ongoing change in the reading ecosystem.
\end{abstract}

\section{INTRODUCTION}

THE main question we posit in the paper is whether the digital transformation can upgrade the status of books from vital to invisible in the technology pyramid. Secondly, we ask which features of the current paper and digital book technology we would want to bring into the future naturalized technology of reading. Asking these questions is more than justified in the context of the current media ecosystem change. In 1992, the New York Times Book Review published Robert Coover's article titled "The End of Books" [1]. In the early 1990s, it was difficult to assess the direction of changes that the Internet would evoke. The digitization process was just beginning. Coover's essay undoubtedly contributed to the mainstream discourse by offering both an observation and a prophecy that literature can be and will be read on electronic screens. The technology of reading became part of the interdisciplinary research agenda. The pace of change, which results from rapid technological progress, causes various reactions among the research community, but voices of those concerned about the fate of the printed word are heard particularly loudly.

Press titles that have been in existence for decades, as well as new entrants to the market, are desperately struggling for survival. As sales of newspapers and magazines plunge,

This work was not supported by any organization publishers are forced to look for new business models. Despite these efforts, some media scholars expect a sudden death of the press. Not only textual media undergo a transformation: audiovisual ones are affected as well. Television channels are losing their audience while niche thematic channels multiply to meet the needs of fragmented audiences. TV channels become increasingly specialized, often focusing on one topic (i.e., cooking, interior design, healthcare).

A parallel trend accompanies this fragmentation: Internet increasingly incorporates other media. One can watch television, listen to the radio, and make video calls via a web connection. The Internet has become an inseparable part of everyday life and, according to Lee Rainie and Barry Wellmann, social media have become an operating system of the contemporary society [2]. The popularization of smartphones and tablets makes this system constantly present and constantly indispensable, and a large number of young adults can no longer imagine their lives without the Web and phones. Studies show that college students generally perceive their cell phones and digital resources as an integral part of who they are, a significant "extension" of themselves [3].

On the other hand, some researchers say that nothing has contributed to the massification of reading activities like the Internet. While this medium is increasingly audiovisual, for the past three decades it has been largely read (since Web 1.0) and even written (since Web 2.0). In as early as 2008, researchers at the University of San Diego, California, estimated that the average American "consumed" over one hundred thousand words per day [4]. They also estimated that compared to 1960 , the percentage of words consumed from paper fell from $26 \%$ to $9 \%$, but it was outweighed by reading from the computer screen: at that time, $27 \%$ of the daily balance of words came from a computer, according to that research. Therefore, the Web and its networks supported reading. Never in history had people read so much. Thus reading is undoubtedly vital, although the digital revolution we are witnessing is changing the media landscape. The 
digital media ecosystem is much more demanding for publishers. It raises the following question: can digital transformation upgrade the status of books from vital to invisible in the technology pyramid?

\section{II.}

OUR QUESTIONS: ARE BOOKS ONLY A VITAL OR AN ALMOST INVISIBLE TECHNOLOGY? HOW CAN BOOKS CONTRIBUTE TO THE EMERGING NATURALIZED TECHNOLOGY OF READING?

Before we focus on the voices and scenarios for the future of reading, let us ask a question about technology levels. Where exactly do books lie in the technology pyramid?

According to Koert van Mensvoort, the author of the pyramid of technology concept [5], every form of technology falls into one of seven hierarchically arranged categories. The higher the level, the more integrated with the human species the technology is. Some technologies evolve, "climbing" to the next levels. Others stop evolving at some level or even slide down to previous phases in their evolution. First, let us look at these seven levels.

Level 1: Envisioned. The first level is about imagination and fantasy. Technology is not here; it functions rather as an emanation of human needs and imagined ideas. Before becoming materialized, inventions, discoveries, and innovations appeared in stories and dreams (e.g., many elements of the twentieth-century technique were described in his novels by Jules Verne; other examples include Leonardo da Vinci and many others).

Level 2: Operational. The next stage is operationalization, i.e. developing prototypes in laboratory conditions, testing, improving and discussing their form.

Level 3: Applied. The third level is the implementation stage: when innovation functions in the natural environment, it is used, initially experimentally, among the innovators.

Level 4: Accepted. This is followed by social acceptance; the invention spreads. To achieve this, time and infrastructure are needed. Technology must adapt to the needs of users and be "tame".

Level 5: Vital. The further life of technology is a gradual transition to, and integration with, social life. At this (fifth) stage, the elimination of the technology would have a dramatic and negative impact on the lifestyle of people and societies because it has become an indispensable element of their existence. One example is the city: it is difficult to imagine modern civilization or banking without cities. It seems that innovations such as telephones, the Internet or smartphones are currently at this level.

Level 6: Invisible. The next, sixth level is the level of "invisibility", where technology becomes indistinguishable from nature, as, for example, in the case of clothing, agriculture or writing.

Level 7: Naturalized. Naturalization is the peak of development, with technologies blending with the nature of homo sapiens, and becoming part of it. Some examples here include thermal processing of food or spoken language.
Now, where are printed books and the press in this hierarchy at present? It seems that printed books, newspapers and magazines are at the fifth stage, i.e. vital. The question is: what next? Will they become invisible? As a consequence of digital transformation and digital access to books, we are witnessing a process of ongoing rejection of paper, but not a rejection of reading as such. What does this mean from the technology pyramid perspective? From this viewpoint, paper is only a specific "larval" form of textual distribution for ideas, concepts, data, information or even wisdom. With the rejection of paper, our text processing will be able to evolve and move to the sixth level, which could take such forms as content displayed directly on the retina.

\section{III.}

\section{THEORIES AND IDEAS: CURRENT READING PHENOMENA IN THREE OVERLAPPING SCENARIOS}

Although our search for an answer begins with literature review, we can begin to answer our central question by asking what happened to horses when cars were introduced. They certainly were vital, but-disrupted by automobiles and cars-horses had never been an invisible technology in transport. It seems that computers, smartphones, tablets and all kinds of other digital screens have captured the time spent reading books, we could assume that books are descending in van Mensvoort's pyramidal hierarchy. Does the digital transformation push books to "descend" from the level of "vital" to the level of "accepted" technology in van Mansvoort's technology pyramid? Is it at all possible to descend from level 5 to level 4 ? We can imagine this process in many scenarios.

There are at least three scenarios for paper books (and, to a degree, also for electronic books). They can be summarized as overlapping scenarios for the future of book reading.

Scenario 1: No paper books, no human need. Paper books are sentenced to gradual extinction in the digital West because Westerners no longer feel that they need to read them.

Scenario 2: Even an invisible technology does not fulfill some human needs which were easily fulfilled in the age of paper. Maybe we will see the developments described by Umberto Eco: "When reading a book, we need to remember what was said on page 20 when we reach page 200 , we need to activate our memory and use our ability to navigate through the space that we have shaped in our imagination while reading. (...) New technologies inspire new forms of creativity (...). And yet, these new forms do not replace the old ones, which we still need dearly." [6].

Scenario 3. The new digital genres and communication forms influence traditional genres and make them superficial. It seems that this third way is also possible. Many scholars point to the renaissance of writing, citing as evidence the gigantic distribution and social circulation of such novel 
series as "Harry Potter", "Game of Thrones", the "Twilight" saga or "The Hunger Games." Is their form the same as that of a twentieth century novel? As Jacek Dukaj observes [7], a new form of storytelling is being born before our eyes, drawing on the digital model. He calls this form a "google novel." As Dukaj writes: "In this way, the novel (and a TV series) artificially satisfies the need, imprinted in the "googled" brain, of continuously hopping to new streams of data: "I can not open another browser window on the pages of the book or enter another chat channel, but before this unconditional reflex tears me away from reading, I'm already in a different story, in a different set design, with other heroes. And again. And again. And again..." [7].

The thick volumes that are making it to bestseller lists are written according to new conventions. Their fictional structure and storytelling manner are very different from the way in which Tolstoy's "War and Peace" or Conrad's "Nostromo" were narrated. They are characterized by three phenomena. The first one are fragmented narratives. The Google-type literature-as Dukaj observes-uses small portions of narratives. The second characteristic is a multiplicity of threads, making it difficult to identify the main character of the story, as in the "Game of Thrones". The third phenomenon within Google-like literature is that talking replaces describing. The dominance of dialogues over descriptions is effort-saving since everyone in the popculture reality knows what an archetypical jungle, a big city or a police station look like, and there is no need to describe them.

Three abovementioned scenarios and some related phenomena can be identified in the interdisciplinary literature review we conducted. According to technological determinism, technology has a formatting effect on humans. New information processing technologies have such a multidimensional and profound impact on users that researchers view this process as progressive formatting of humans through technology. Neil Postman was a prophet of such technological formatting [8]. Technology becomes the operating system of everyday life but it can also cause dysfunctions. Trend researchers and sociologists, among them John and Nana Naisbitt along with Douglas Phillips [9], formulate a diagnosis that people in America are still in a state of technological intoxication. They describe six signs of such a state of mind: 1) Favoring ad hoc solutions, from religion to food; 2) Worship of technology and fear of it; 3) Bridging the differences between what is real and what is pretended; 4) Taking violence as a normal thing; 5) Loving technology, as one loves a toy; 6) Experiencing one's life, being distanced and distracted.

The "man of numbers" replaces the "typographic man". After 25 years, the pessimistic voices expecting an apocalypse of books entailed by the popularization of electronic screens, sound ever louder. Gołębiewski [10] proposes an alarming vision, in which the impact of digital screens will cause the traditional reading of literature (i.e. from paper) to degenerate. Reading from old-fashioned paper "interfaces" [11], as envisioned by Gołębiewski, will be pushed into the ghetto of anachronistic connoisseurs, which will exist alongside the mainstream culture in the same way as the current ghettos of cassette or vinyl record lovers. He points out, after Marshall McLuhan [12], that Gutenberg's invention of print created a "typographic man". The world of the "typographic man" facilitated the dissemination of education, invented and disseminated the press and gave broad access to literature through libraries. It also created the novel which throughout the nineteenth century and until the invention of the motion pictures was the default form of storytelling. According to Gołębiewski, the world of the "typographic man" is currently undergoing a process of degeneration.

Researchers worry about the future of in-depth reading. There is a growing concern that immersion in digitally mediated modes of knowledge acquisition might hinder or even eliminate mental activities that emerged from interactions with traditional media, and which are still tremendously valuable. The leading example here is the concern about the demise of "deep reading", a practice traditionally associated with interacting with long, linear texts. It is understood as the practice of, and ability to concentrate on, reading long texts for extended periods of time, with the aim of enhanced comprehension, construction of meanings, and facilitation of "deep learning" [13]. Research results suggest that the cognitive performance of even skilled comprehenders might be hindered if critical sections of digital media learning material are only scanned [14]. The skill of deep reading, trained in interaction with traditional books and longer printed texts, is argued to be essential for developing the faculties of critical thinking, reasoning, and insight. The logic of hypertext and multitasking, vital for proficient navigation in the digital world, is supposed to shape brains and habits in a way that makes deep reading practices less viable $[15,16]$. Maryanne Wolf [17] notes that reading is something that the human brain has not evolved into. Among various forms of communing with culture, reading is the one to which nature has not prepared humans through the process of adaptation.

From the brain neuroplasticity perspective, reading is changeable, not given. Since we do not have a genetic instruction on how to read (while we have instructions on how to look, listen or smell), reading skills require training that is not easy and takes time. It is worth considering how digital developments affect activities such as reading. The Internet, a new medium originally conceived as a text medium, is becoming increasingly pictorial and visual. Also, the popularity of new smartphone applications suggests that young people increasingly need to express themselves through images (using Snapchat, Instagram, or Pinterest). In other words, extensive training in reading books and longer texts (which children are subjected to at school) is supplemented (perhaps even gradually dominated) by 
training in the use of random, short texts, accompanied by graphics.

When humans are learning to read, their brain must adapt to the process physically and internal resources must be managed. This "development" has the most physical character: new connections are being created in the brain. The existing ones (i.e. shape recognition, sound recognition) are harnessed to new functions. Resources and created connection systems must then be fixed and trained, which requires long hours of interaction with texts, and arduous learning. Finally, the brain becomes adapted to reading and becomes compatible with the type of information that it will stages up to the final. This is how an essay, a novel or a scientific lecture is structured. Using an Internet browser is closer to scanning, where the gaze scans the screen in search of interesting content, and anchors on those points that are most likely to solve the problem or offer something interesting. A new website is scanned, an item is found and clicked on. Then a new page is opened and the process begins again.

There is also a new phenomenon at the doorstep: we are moving from codices to scrolls. Dissemination of smartphones and tablets has slightly redefined the use of the Web, introducing the use of applications (known as apps).

TABLE I.

Textual "DieT" of Poles [21]

\begin{tabular}{|c|c|c|}
\hline & yesterday & a year ago \\
\hline \multicolumn{3}{|l|}{ Texts on paper } \\
\hline Articles in printed daily newspapers or general-interest magazines & $37 \%$ & $35 \%$ \\
\hline Books - novels, stories, biographies, non-fiction & $18 \%$ & $26 \%$ \\
\hline Short texts such as advertisements, informational messages, inscriptions on walls, leaflets, etc. & $18 \%$ & $16 \%$ \\
\hline Manuals, training materials & $9 \%$ & $11 \%$ \\
\hline Articles in industry and specialist magazines & $7 \%$ & $9 \%$ \\
\hline Tutorials and guidebooks & $6 \%$ & $8 \%$ \\
\hline Poetry & $5 \%$ & $6 \%$ \\
\hline Comic books, albums & $1 \%$ & $2 \%$ \\
\hline \multicolumn{3}{|l|}{ Text on screen } \\
\hline Short text messages: texts, tweets, single-sentence posts & $38 \%$ & $32 \%$ \\
\hline Short entries and messages on the Internet: on blogs, forums, social media, e-mails & $31 \%$ & $26 \%$ \\
\hline Longer texts on the Internet such as articles on blogs, websites, etc. & $18 \%$ & $17 \%$ \\
\hline
\end{tabular}

process. Consequently, the brains of people using different types of writing are physically different from one another. When reading the Latin alphabet, Westerners activate the left hemisphere while reading. In contrast, Chinese (logographic) script requires the use of both hemispheres. Interesting in this light is that Japanese readers simultaneously use their own form of logographic writing and a type of syllabic writing, consisting of 46 characters (the so-called kana script), and used to write their own names.

Neuroimaging studies have demonstrated [17] how the brain operation changes depending on whether it decodes logographic or syllabic writing. Maryanne Wolff's analysis shows that the brains of people using different types of writing function differently and they also process information differently.

According to Nicholas Carr [18], about four hours of Surfing the internet is enough for the brain to switch to a slightly different mode of operation. Reading a text such as a book is (and must be) analog in nature - this is a continuous process where we accompany the author throughout the whole argument: from the beginning, through subsequent
Technological limitations (small screens and the inability to use the cursor, inherently targeting small objects on the screen more accurately than a finger) have put virtual content navigation into the hands of virtual image scrolling. The socalled "scrolling" is reminiscent of scrolling a large (sometimes almost endless) physical scroll. This is an interesting sign of our times where, after centuries of dominance of books in the form of "codices" (with sheets stapled or glued on one side), we are witnessing a gradual return to the scroll format (this time a virtual one). In antiquity, the codex format had an undoubted advantage, giving users the possibility of free and quick access to any place of the text, whereas a scroll required arduous physical scrolling (also performed through technically when using a music cassette or a VHS tape). Today, Facebook or Twitter users do not seem to need such a feature: a continuous stream of notifications from friends (and strangers who are tagged as "friends") is just a stream, a flow, something that is happening here and now.

In his works, Łukasz Gołębiewski claims that the digital revolution that changes our habits of media consumption will 
change our civilization. "There has been a terrible thing that happened to readership. It has been reduced to mindless activities. We live in a time of breakthrough, the generation of those raised on books is still statistically large enough to give the illusion that the world is still normal. But this is an illusion. A new generation, called Digital Natives, has grown up in front of a computer monitor. They have other needs and are effectively pushing them." [19]

So can reading disappear at all? Can we imagine a world without books? No libraries or press? At this point, it is worth considering how much these information processing and gathering technologies are fused with our civilization. Our civilization does not want us to withdraw from linear reading. One of the eminent fruits of digital transformation is Amazon Kindle.

As we mentioned in this literature review, according to some voices the digital revolution is expected to eliminate the "typographic men" and replace them with the "men of numbers" because exposure to information is now mediated through electronic screens and digital media. The future world is painted by extrapolation as a place with falling circulation of magazines and newspapers, and declining book spending. For the "man of numbers", cursory cognition is the default mode of operation. These humans do not go deeply into the content, and live in constant inattention in multiple channels, among applications, screens, programs and chats. The "men of numbers" also consume culture differently: they listen to mp3s rather than CDs or vinyl records, Spotify playlists rather than music albums, they search for information in Google or Wikipedia rather than in an encyclopedia, they draw on a tablet app rather than using a pencil. Such descriptions evoke the image of humans affected by all five symptoms listed by John and Nana Naisbit.

Taking into account the context of readership, it is worth considering whether the metaphor of the "man of numbers" against MacLuhan's "typographic man" is correct. When reading a book purchased from Amazon on an electronic reader, the reader does not consume digits but letters. It is the same when surfing the Internet and reading characters displayed on the LCD screen. The fact that these characters are digitally coded is irrelevant to human perceptual apparatus. When they read, the hypothetical "men of numbers" read letters. Doubts also arise when we try to equalize all types of electronic screens, as Gołębiewski would like.

Meanwhile, reading from an electronic Kindle reader (or many of its varieties produced and sold under other brands) has completely different qualities than reading from a screen of a smartphone or a tablet. The functionalities of an ebook reader are undoubtedly narrower than those of a smartphone. The latter has many functions that can disrupt concentration. For example, they may generate the need to check e-mails or respond to Facebook conversation threads. The paper versus electronic screen dichotomy is probably too simple and, in effect, it obscures the real image of the phenomenon of digital reading. From this perspective, one can try to categorize "reading interfaces" regarding their potential ability to narrow attention. The screen of an electronic reader (e-reader) would be much closer to paper than to a computer screen. We liken it with cuneiform script rather than a scroll or a codex.On the other hand, it is beyond doubt that people consume ever more information from computer screens (which includes learning from digital media), so it is reasonable to consider whether a change in the medium causes triggers a change in reading habits, i.e. in what, how and why we read and how we obtain information. In this context, the ability to use screens for reading is a prerequisite for proficient usage of digital resources and for taking part in electronically mediated activities, with learning being the most important one. Moreover, Kindle is not the same as Google. It is the post-digital hybrid of cuneiform script, a scroll and a codex. Kindle is technology that enables deep reading. Symbolically speaking, Google and Kindle are two

TABLE II.

EVALUATION OF BOOK AND NON-BOOK TEXTS ON FIVE DIMENSIONS OF THE RESPONDENTS' FEELINGS. DATA PRESENTATION BY MiCHAE Feliksiak and Barbara Badora, Public Opinion Research Center [21]

\begin{tabular}{|c|c|c|c|c|c|}
\hline Type of text read yesterday & \multicolumn{5}{|c|}{ For me, this text was } \\
\hline $\begin{array}{l}\text { Average results on a scale from } 1 \text { to } 7, \text { where } 1 \text { means } \\
\text { "does not apply at all" and } 7 \text { means "applies completely" }\end{array}$ & $\begin{array}{l}\text { Significant, } \\
\text { important }\end{array}$ & $\begin{array}{l}\text { Touching, } \\
\text { moving }\end{array}$ & $\begin{array}{l}\text { Thought } \\
\text { provoking }\end{array}$ & $\begin{array}{l}\text { Initiating a } \\
\text { conversation }\end{array}$ & $\begin{array}{l}\text { Useful, } \\
\text { helpful }\end{array}$ \\
\hline Books & 4.90 & 3.75 & 4.98 & 4.90 & 5.12 \\
\hline Articles in trade press and specialist magazines & 5.14 & 2.30 & 4.43 & 4.55 & 5.43 \\
\hline Short text messages: texts, tweets, single-sentence posts & 3.88 & 2.14 & 2.71 & 2.94 & 4.06 \\
\hline $\begin{array}{r}\text { Short entries and messages on the Internet: on blogs, } \\
\text { forums, social media, e-mails }\end{array}$ & 3.82 & 2.21 & 3.39 & 3.48 & 4.21 \\
\hline $\begin{array}{r}\text { Longer texts on the Internet such as articles on blogs, } \\
\text { websites, etc. }\end{array}$ & 4.33 & 2.59 & 4.21 & 4.23 & 4.58 \\
\hline $\begin{array}{l}\text { Short texts such as advertisements, informational messages, } \\
\text { inscriptions on walls, leaflets, promotional leaflets, etc. }\end{array}$ & 2.43 & 1.58 & 2.30 & 2.48 & 3.15 \\
\hline $\begin{array}{r}\text { Articles in printed daily newspapers or general-interest } \\
\text { magazines }\end{array}$ & 4.28 & 3.38 & 4.27 & 4.37 & 4.56 \\
\hline Comic books, albums & 3.06 & 3.13 & 3.19 & 3.50 & 3.90 \\
\hline
\end{tabular}


contradictory faces of the same process.

IV.

\section{EMPIRICAL OBSERVATIONS: WHAT DOES AN ATTEMPT OF TOTAL RESEARCH INTO LITERARY CULTURE TELL US ABOUT PAPER AND DIGITAL READING?}

What is similar and what is different in digital reading and paper reading? Is digital reading almost the same as analog reading on paper? Do we think of the same kind of reading? We draw our answers from a research project where a national representative random sample of Poles was asked about their reading habits in the digital era a few years ago.

The project entitled "Directions and forms of reading transformation in Poland" consisted of data from personal interviews (CAPI and CAWI), short interviews with visitors to a book fair, qualitative data from household ethnography and expert discussion, which were then all merged with readership research and book market statistics. Some of us co-authored the research led by Warsaw-based state-funded National Information Processing Institute, with Krzysztof Krejtz as its scientific coordinator. We refer to this research not only because we co-authored it and can be proud of its "enormous cognitive potential" [20], noted as a step towards "total research into the literary culture" [20]. We believe that its results illustrate and deepen our insights into reading technology [21, 22].

Results 1: Retrospective panel data on how respondents read yesterday and a year ago. Part of the survey was conducted using the so-called retrospective panel method. It is not a comparison of two measurements taken in separate moments in time but, rather, a kind of synthetic selfreflection obtained from the respondents.

The respondents were asked what and where they had read on the day before the survey and one year before the survey. Among answers, the respondents could select not only books but also different types of text. This is visible in the answers shown in Table 1. Respondents admit that during the preceding year they read fewer books than shorter messages and entries on the Internet and mobile devices such as smartphones or tablets.

Results 2: Declarative data on how respondents felt about different kinds of texts. While looking for ways of getting an insight into almost intimate issues of readers' relations to a book (as well as other textual) "interface", in one set of survey questions we asked how the respondents felt after reading books and non-book texts on the previous day. The respondents were asked to evaluate previous-day texts using five seven-point scales, where 1 meant that the statement did not apply at all to the text they read and 7 meant that the statement applied completely to the readers' experience.

We checked the five dimensions of the assessment:

Dimension 1: Importance. First of all, we asked if the text was "significant, important" for the respondents.
Dimension 2: Emotional impact. Secondly, we were interested in how much the text was "moving, touching" for them.

Dimension 3: Thoughtfulness. The third dimension was the extent to which the text prompted the respondents to think.

Dimension 4: Sociability. We were also interested in the social dimension, i.e. to what extent the text encouraged the respondents to talk about it.

Dimension 5: Usefulness. The fifth dimension was the extent to which the text turned out to be "useful" for the respondents.

After conducting statistical tests, we learnt that books are rated significantly higher than all other texts read on the day preceding the survey, on each dimension tested. Articles in trade press and specialist magazines performed similarly: in terms of four dimensions, they were ranked close to books, but they failed to move readers emotionally. Detailed results are presented in Table 2 .

While juxtaposing these results with his idea of literacy culture total research, Maciej Maryl [20] noted: "The concept of "textual diet", i.e. the diversity of the types of texts that the recipients are acquainted with, proposed by Toczyski and Krejtz, may prove useful. However, it would be necessary to refine this catalog in such a way as to avoid mixing up formal determinants (e.g. length of the text, paper vs. electronic format) with genres (e.g. novels, poetry, guides).

We find this criticism justified. However, we still recommend separating digital and analog forms, so that we have a better idea about the place of Web versions, and the place of print versions in readers' textual diet. Fortunately for the present paper, even despite the mix of genres, lengths, and formats, we can see the dominance of books on almost every dimension, which proves their position.

Results 3: Ethnographic interviewing and observing readers as users. The analysis of ethnographic interviews conducted under the same project shows that reading from an LCD screen and paper are two different worlds. Reading from a screen is primarily done for work (e-mails, electronic documents, work with software) and entertainment (short "fillers of time" when there is a break at work). These fillers can be social media posts, funny drawings (memes), information on portals and other things [22]. The reader does not delve into the topic, which is a result of performing many activities at once. Everything works in parallel mode on the Internet. Running a conversations in a chat box does not prevent users from holding a second conversation in parallel, making online purchases, listening to music or playing a game.

Reading from paper, be it books or newspapers, belongs to the realm of luxury and pleasure. So, what are the barriers that prevent paper-based reading from becoming part of everyday life? We found three types of barriers. 
Barrier 1: Time. The main limitation is connected with time. In order to delve into a narrative, we need to find more free time. Paper texts have ceased to function as "gap fillers".

Barrier 2: Distractors. Other barriers mentioned in the study included the barrier of concentration: even if you do have some free time, if you want to immerse in reading, you should devote yourself to it and exclude yourself from other activities. This is difficult due to the excessive burden of everyday duties. Also, many media and leisure activities, often more attractive (TV, computer, smartphone), are fighting for people's attention. Worth noting is that a smartphone with apps generating a continuous stream of interrupts ("you have a message", "you have an email", "your post has been commented on") becomes a distracting trap and a generator of constant temptations to check what is going on without our participation.

Barrier 3: Mode-switching. The third type of barrier that emerged in ethnographic interviews was the "transition barrier". By this we mean the process of switching attention to a focused mode. For many people, this is so unobvious and difficult that they need various kinds of rituals, such as a favorite chair, tea, absolute silence (hence, the natural time for book reading comes in the evening, at bedtime).

What emerges from this research is an image where an easy, pleasant and entertaining text (usually read from the screen) displaces more ambitious content read on paper. The victims of this process are not only the shrinking book expenditures but also printed newspapers and magazines (however, they seem more accessible due to their volume: in a busy schedule, it is easier to accommodate a single article than a section of a book).

$\mathrm{V}$.

\section{OPENING REMARKS: INSTEAD OF A CONCLUSION}

The whole technology-related and work-related social system makes people read, but in a distracted way, probably not fulfilling many of their needs which could be met by the written word. Within the scope of the three elements discussed here, i.e. technology, biology and culture, the former one seems to dominate at present, suppressing the other two. All three create a triad where each element dynamically shapes the other two. The example of reading is illustrative in showing that currently, i.e. since the 1990s, peaking in the 2010s, technology is in the lead while the other two elements are only forced to adapt.

We began this analysis with technology levels shown as a seven-level pyramid. We asked about the position of books in this pyramid. We discussed some theories to find out whether books could become an invisible technology. We showed some encouraging data illustrating our approach (both quantitative and qualitative). Finally, with the above work, we intend to open a discussion, not even trying to reach final conclusions on any part. The ongoing digital transformation is leading us towards many fundamental questions about civilization founded on letters, which require further interdisciplinary studies involving the high tech industry, human-computer interaction experts, and social theory readers. One such question is what the invisible technology of reading will be like. Which qualities of traditional books will this new technology use? Which aspects of books do we want to transfer to the invisible (and ultimately the naturalized) technology of reading?

\section{REFERENCES}

[1] R. Coover, The End of Books, New York Times Book Review, 1992.

[2] H. Rainie and B. Wellman, Networked: The new social operating system. Cambridge, Mass: MIT Press, 2012.

[3] R. Belk. "Extended Self in a Digital World" Journal of Consumer Research, 2013, vol. 40(3), pp. 477-500.

[4] How Much Information? Report on American Consumers, San Diego, 2009.

[5] K. van Mensvoort, Pyramid of Technology: How Technology Becomes Nature in Seven Steps. Eindhoven: Technische Universiteit Eindhoven, 2013.

[6] U. Eco. Nowe środki przekazu a przyszłość książki. Warsaw: Państwowy Instytut Wydawniczy, 1996 (translation of the quote by the authors)

[7] J. Dukaj, "Za dhugie, nie przeczytam..." Tygodnik Powszechny (Oct. 17, 2010).

[8] N. Postman, Technopoly: Surrender of Culture to Technology, New York: Vintage Books, 1993

[9] J. Naisbitt, N. Naisbitt, D. Philips. High tech, high touch: Technology and our search of Meaning, New York: Broadway, 1999.

[10] L. Gołębiewski. Śmierć ksiażki. No Future Book, Warsaw: Biblioteka analiz, 2008

[11] L. Manovich. The language of new media. Cambridge, Mass: MIT Press, 2001

[12] M McLuhan, The Gutenberg Galaxy: The making of typographic man, Toronto, University of Toronto Press, 1962.

[13] J. C. Roberts and K. A. Roberts. "Deep Reading, Cost/Benefit, and the Construction of Meaning: Enhancing Reading Comprehension and Deep Learning in Sociology Courses" Teaching Sociology, vol. 36(2), 2008, pp. 125-140.

[14] L. Salmeron, J. Naumann, V. Garcia and I. Fajardo. "Scanning and deep processing of information in hypertext: a cued retrospective think aloud study" Journal of Computer Assisted Learning, vol. 33, 2017, pp. 222-233.

[15] M. Wolf, Our 'Deep Reading' Brain: Its Digital Evolution Poses Questions. Nieman Reports, vol. 64(2), 2010, pp. 7-8.

[16] M. Wolf and M. Barzillai. "The Importance of Deep Reading" Educational Leadership, vol. 66(6), 2009, pp. 3-37.

[17] M. Wolf, Proust and the Squid: The Story and Science of the Reading Brain, New York: Harper Perrenial, 2007.

[18] N. Carr, The Shallows: What the Internet Is Doing to Our Brains, New York: W. W. Norton \& Company, 2011.

[19] L. Gołębiewski. Gdzie jest czytelnik? Warsaw: Biblioteka Analiz, 2012.

[20] M. Maryl. "Kulturowa piśmienność: projekt badań totalnych kultury literackiej" Teksty Drugie, 2015, vol. 3, pp. 9-29.

[21] P. Toczyski and K. Krejtz. "Dieta tekstowa Polaków. Rola i znaczenie książki na tle innych tekstów" in Raport Polskiej Izby Książi z projektu badawczego Kierunki i formy transformacji czytelnictwa $w$ Polsce 2013-2014, P. Toczyski, J. Kowalski, A. Niedzielska, K. Krejtz, P. Kobyliński. Ed. Warsaw: Polska Izba Książki, 2014. pp. $30-41$.

[22] J. Kowalski. "Od papieru do LCD. Wnioski z wywiadów etnograficznych" in Raport Polskiej Izby Ksiązki z projektu badawczego Kierunki $i$ formy transformacji czytelnictwa $w$ Polsce 2013-2014, P. Toczyski, J. Kowalski, A. Niedzielska, K. Krejtz, P. Kobyliński. Ed. Warsaw: Polska Izba Książki, 2014. pp. 42-49. 